\title{
Ventilatory efficiency testing as prognostic value in patients with pulmonary hypertension
}

\author{
Martin Schwaiblmair, Christian Faul, Wolfgang von Scheidt and Thomas M Berghaus
}

\begin{abstract}
Background: Increased ventilatory response has been shown to have a high prognostic value in patients with chronic heart failure. Our aim was therefore to determine the ventilatory efficiency in pulmonary arterial hypertension and chronic thromboembolic pulmonary hypertension by cardiopulmonary exercise testing (CPET) identifying PH-patients with increased risk for death within 24 months after evaluation.

Methods: 116 patients (age: $64 \pm 1$ years) with a mean pulmonary arterial pressure of $35 \pm 1 \mathrm{mmHg}$ underwent CPET and right heart catheterization. During a follow-up of 24 months, we compared the initial characteristics of survivors $(n=87)$ with nonsurvivors $(n=29)$.

Results: Significant differences $(p \leq 0.005)$ between survivors and nonsurvivors existed in ventilatory equivalents for oxygen (42.1 \pm 2.1 versus $56.9 \pm 2.6)$ and for carbon dioxide (Ve/NCO2) $(47.5 \pm 2.2$ versus $64.4 \pm 2.3)$. Patients with peak oxygen uptake $\leq 10.4 \mathrm{ml} / \mathrm{min} / \mathrm{kg}$ had a 1.5 -fold, VeNCO2 $\geq 55$ a 7.8 -fold, alveolar-arterial oxygen difference $\geq 55 \mathrm{mmHg}$ a 2.9 -fold, and with VeNCO2 slope $\geq 60$ a 5.8 -fold increased risk of mortality in the next 24 months.

Conclusions: Our results demonstrate that abnormalities in exercise ventilation powerfully predict outcomes in $\mathrm{PH}$. Consideration should be given to add clinical guidelines to reflect the prognostic importance of ventilatory efficiency parameters in addition to peak VO2.
\end{abstract}

\section{Background}

Most patients with pulmonary hypertension (PH) have exercise limitation attributing to an impaired vasodilator response of the pulmonary arteries during exercise. Cardiopulmonary exercise testing (CPET) describes the underlying physiologic abnormalities associated with the underperfusion of the pulmonary vascular bed seen in PH [1-6]. Additionally, CPET allows reproducible assessment of functional capacity and treatment efficacy in patients with $\mathrm{PH}[2,5,7-10]$.

Peak oxygen uptake (VO2) is the most frequently analyzed CPET parameter and has consistently demonstrated prognostic significance. Other ventilatory expired gas parameters obtained during exercise testing have recently demonstrated prognostic value. The relationship between minute ventilation and carbon dioxide production (Ve/VCO2 slope) is one of such CPET parameter

\footnotetext{
* Correspondence: martin.schwaiblmair@klinikum-augsburg.de

Department of Internal Medicine I, Klinikum Augsburg, Ludwig Maximilians University of Munich, Munich, Germany
}

(c) 2012 Schwaiblmair et al.; licensee BioMed Central Ltd. This is an Open Access article distributed under the terms of the Creative Commons Attribution License (http://creativecommons.org/licenses/by/2.0), which permits unrestricted use, distribution, and reproduction in any medium, provided the original work is properly cited. that appears to have clinical value. It can be derived patient motivation. The $\mathrm{Ve} / \mathrm{VCO} 2$ slope is inversely related to cardiac output at peak exercise [11] and is at least partly explained by a decrease in pulmonary perfusion $[12,13]$. Ventilatory efficiency was found to be reliable predictor of prognosis in patients with chronic heart failure [14-22].

Since inefficiency of ventilation results from decreased perfusion of the ventilated lung, for example by an increased physiological dead space ventilation, a high ventilatory response relative to metabolic demand would be expected [23]. If a simple non-invasive measurement, such as the VE/VCO2 ratio, could be shown to be useful in evaluating pulmonary vascular disease, it might serve to supplement other methods currently used to monitor clinical course and treatment. At now, few studies have investigated the relationship between exercise capacity and VE/VCO2 slope in patients with $\mathrm{PH}[24,25]$.

Despite recent advances in pharmacological treatment of patients with $\mathrm{PH}$, mortality rates, especially in 
patients with severe pulmonary artery hypertension $(\mathrm{PAH})$, remain high. Reliable risk stratification is a continuing challenge and the identification of patients at highest risk for early death from right heart failure is of special importance. Functional capacity, as defined by peak VO2 during CPET is established as a powerful predictor of mortality in $\mathrm{PAH}[26,27]$ and a peak $\mathrm{VO} 2$ below $10.4 \mathrm{~mL} / \mathrm{kg} / \mathrm{min}$ is now considered a key criterion for early mortality [2]. To date however, differences in the prognostic value of peak $\mathrm{VO} 2$ and the $\mathrm{Ve} / \mathrm{VCO} 2$ slope have not been widely emphasized.

In this study, we determine the predictive value of ventilatory efficiency parameters for estimating the 2years survival of patients with pulmonary arterial hypertension (PAH) and inoperable chronic thromboembolic pulmonary hypertension (CTEPH) and compare these parameters with survival predicted by peak VO2.

\section{Methods}

\section{Subjects}

This study included consecutive patients who were referred to our PH centre from January 2005 to January 2008 to confirm and to classify the $\mathrm{PH}$, as defined by the Proceedings of the $4^{\text {th }}$ World Symposium on Pulmonary Hypertension [26]. All patients underwent right heart catheterization (RHC) to establish the diagnosis, pulmonary function testing, six-minute walking test and a progressively increasing, symptom-limited CPET with gas exchange measurements. All patients did not receive any specific pulmonary artery medication at the beginning of the study. Patients with severe concomitant extracardiac diseases limiting exercise performance were excluded.

All patients were followed at the PH centre, Klinikum Augsburg, University of Munich. The outcome data were collected by patient's visit every 3 months. The minimum follow-up period was 24 months.

All procedures adhered to the commonly accepted ethical guidelines, the protocol was initially reviewed and approved by an Ethics Committee and written informed consent was obtained from every patient.

\section{Lung function tests}

Pulmonary function tests included spirometry, body plethysmography, and measurement of diffusing capacity employing the single breath method (Master Screen Body and MS-PFT, Jaeger, Cardinal Health, USA). Each parameter was calculated as percent of predicted [28]. The following parameters were determined: forced vital capacity (FVC), total lung capacity (TLC), forced expiratory volume in one second (FEV1) and diffusing capacity for carbon monoxide (TLco). Blood gas analysis (ABL 725, Radiometer, Copenhagen, Denmark) was performed in arterialized capillary blood from the ear lobe without supplemental oxygen [29].

\section{Six-minute walk test}

Measurement of the distance walked in 6 min was performed in all patients according to the standards of the American Thoracic Society [30]. The patients were instructed to walk back and forth at their own pace in a $30-\mathrm{m}$ corridor in order to cover as much ground as possible in the allotted time. A research assistant supervised the test, telling the patient the remaining exercise time every $2 \mathrm{~min}$. The patients were allowed to stop and take at rest during the test, but were instructed to resume walking as soon as possible.

\section{Cardiopulmonary exercise testing}

CPET was performed using standardized protocol [31]; work rate was continuously increased by $5-15 \mathrm{~W} / \mathrm{min}$ to a maximum tolerated level on an electromagnetically braked cycle ergometer (ViaSprint 150 p, Ergoline, Germany). Patients were encouraged to exercise until symptoms were intolerable.

Blood gas analysis was analyzed at rest and during maximal exercise. Heart rate was monitored continuously, and non-invasive blood pressure was taken every 2 min. The maximum work rate was recorded. Oxygen uptake (VO2), minute ventilation (Ve), and carbon dioxide output (VCO2) were measured breath by breath wearing an adult facemask (Vmax spectra $229 \mathrm{D}$, Sensor Medics, CA, USA). Peak VO2, oxygen pulse (O2 pulse) and alveolar-arterial oxygen difference $(\mathrm{AaDO} 2)$ were calculated as described by Wasserman et al. [31]. The anaerobic threshold (AT) was chosen as the VO2 at which the $\mathrm{Ve} / \mathrm{VO} 2$ increased while the $\mathrm{Ve} / \mathrm{VCO} 2$ decreased or remained constant. Peak VO2 was defined as the value of averaged data during the final 15 seconds of exercise. The Ve/VCO2 slope was determined as the linear regression slope of $\mathrm{Ve}$ and $\mathrm{VCO} 2$ from the start of exercise until the $\mathrm{RC}$ point (the time at which ventilation is stimulated by $\mathrm{CO} 2$ output and end-tidal $\mathrm{CO} 2$ tension begins to decrease) [31].

\section{Right heart catheterization}

All patients underwent RHC. Patients received no medications on the morning of the procedure, resulting in a discontinuation of treatment with medication of about 12 h. A True Size Thermodilution Catheter ("S" Tip Catheter, Edwards Lifesciences, Irvine, CA, USA) was inserted via the right femoral vein. Hemodynamic measurements were performed in supine position and included heart rate, pressure in wedge-position (PCWP), pulmonary arterial pressure (PAP) and right atrium pressure (RA). Oxygen saturation (SO2) was measured in mixed venous blood samples (ABL 725, Radiometer, 
Copenhagen, Denmark). Cardiac index (CI) was obtained using the thermodilution method (Com-2, Cardiac Output Computer, Edwards Lifesciences, Irvine, CA, USA). CI and pulmonary vascular resistance (PVR) were calculated using standard formulas $[\mathrm{PVR}=(\mathrm{mPAP}-$ PCWP)/Q].

\section{Statistical analysis}

Continuous date were presented as the mean \pm standard error of mean (SEM); categorical data were presented as percentages of patients in each category. A statistical software package (SPSS, version 12.0 for Windows; SPSS; Chicago, IL) was used for analysis. All results were tested for two-sided significance. Patients were divided in two different groups regarding the outcome after 24 months. The measured variables were compared in the group of survivors versus the group of nonsurvivors using the Student $t$-test for unpaired probes.

Simple linear regression analysis was used to examine ve versus VCO2 slope. Test analysis was performed to calculate sensitivity, specificity for the different threshold values.

Furthermore, we used the Wald test to test for the significance of odds ratio. The ability of CPET parameters to identify the risk of mortality was assessed by comparison of receiver-operating characteristic curves (AUC= area under curve). We create survival curves using the method of Kaplan and Meier and compare the survival curves using the log-rank test.

In general, $\mathrm{p}$-values $<0.05$ were considered to be statistically significant.

\section{Results}

\section{Clinical characteristics}

The study included 116 patients; there were 73 women and 43 men with a mean age of $63.7 \pm 1.7$ years and a body mass index of $26.7 \pm 0.4 \mathrm{~kg} / \mathrm{m}^{2}$. According to the ESC/ERS guidelines [27], we diagnosed 85 patients as $\mathrm{PAH}$ and 31 as inoperable CTEPH [Table 1]. At the initial visit, all patients fulfilled the criterion to begin a specific drug therapy. During follow-up, the specific drug therapy consisted calcium channel blockers in 7\%, inhaled prostanoids in $13 \%$, endothelin receptor antagonists in $72 \%$ and $56 \%$ patients were treated with phosphodiesterase type-5 inhibitors. None of the patients was lost to follow-up. During the follow-up period of 24 months, 29 patients died $(n=21$ in the PAH-group and $n=8$ in the CTEPH-group). Causes of

Table 1 Characteristics, haemodynamics and Cardiopulmonary exercise parameters at baseline of the overall group $(n=116)$ and between patients with PAH $(n=85)$ and those with CTEPH $(n=31)$

\begin{tabular}{|c|c|c|c|c|}
\hline & Overall & PAH & СTEPH & $p$ \\
\hline & $(n=116)$ & $(n=85)$ & $(n=31)$ & \\
\hline Age (years) & $61.5 \pm 1.5$ & $59.9 \pm 1.9$ & $66.4 \pm 2.0$ & $p=0.064$ \\
\hline Sex (\% female) & 66 & 70 & 55 & ns \\
\hline $\mathrm{BMI}(\mathrm{kg} / \mathrm{m} 2)$ & $25.8 \pm 0.5$ & $25.7 \pm 0.6$ & $26.2 \pm 0.7$ & ns \\
\hline PAP, $\mathrm{mmHg}$ & $39.9 \pm 2.5$ & $40.5 \pm 1.7$ & $38.3 \pm 3.1$ & ns \\
\hline $\mathrm{Cl}, \mathrm{L}^{*} \mathrm{~min}-1^{*} \mathrm{~m}-2$ & $2.48 \pm 0.07$ & $2.58 \pm 0.08$ & $2.22 \pm 0.11$ & $p=0.021$ \\
\hline PVR, dynes * s* cm-5 & $648.2 \pm 40.2$ & $647.9 \pm 45.1$ & $\begin{array}{c}648.9 \pm 87.5 \\
\text { ns }\end{array}$ & \\
\hline $\mathrm{RAP}, \mathrm{mmHg}$ & $7.28 \pm 0.49$ & $7.01 \pm 0.56$ & $8.07 \pm 1.00$ & ns \\
\hline W, watts & $56.2 \pm 3.1$ & $55.2 \pm 3.7$ & $59.1 \pm 5.5$ & ns \\
\hline $\mathrm{VO} 2, \mathrm{ml} / \mathrm{min} / \mathrm{kg}$ & $14.4 \pm 0.7$ & $14.5 \pm 0.8$ & $14.1 \pm 1.2$ & ns \\
\hline AT, $\mathrm{ml} / \mathrm{min} / \mathrm{kg}$ & $9.53 \pm 0.40$ & $9.56 \pm 0.48$ & $9.45 \pm 0.72$ & ns \\
\hline $\mathrm{O} 2$ pulse, $\mathrm{ml} / \mathrm{min} /$ beat & $8.98 \pm 0.36$ & $8.71 \pm 0.40$ & $9.72 \pm 0.81$ & ns \\
\hline VeNO2 - AT & $41.1 \pm 1.1$ & $40.9 \pm 1.2$ & $41.8 \pm 2.3$ & ns \\
\hline VeNCO2 - AT & $47.2 \pm 1.1$ & $47.0 \pm 1.2$ & $47.8 \pm 2.5$ & ns \\
\hline AaDO2 (peak exercise) & $\mathrm{mmHg} 49.3 \pm 1.6$ & $51.6 \pm 1.9$ & $43.2 \pm 2.9$ & $p=0.019$ \\
\hline a-et $\mathrm{CO} 2, \mathrm{mmHg}$ & $5.7 \pm 0.5$ & $5.2 \pm 0.5$ & $7.0 \pm 1.0$ & ns \\
\hline VeNCO2 slope & $46.9 \pm 2.0$ & $46.6 \pm 2.3$ & $47.9 \pm 3.9$ & ns \\
\hline
\end{tabular}

$W=$ work capacity.

VO2 = peak oxygen uptake.

$A T=$ anaerobic threshold.

O2 pulse = oxygen pulse.

$\mathrm{Ve} / \mathrm{VO} 2$ = oxygen equivalent at anaerobic threshold.

$\mathrm{Ve} / \mathrm{CO} 2$ = carbon dioxide equivalent at anaerobic threshold

$\mathrm{AaDO} 2=$ alveolar-arterial oxygen difference at peak exercise.

a-et $\mathrm{CO} 2=$ arterial-endexpiratory carbon dioxide difference at peak pexercise.

$V e-V C O 2$ slope $=$ slope of minute ventilation versus carbon dioxide output. 
death were progressive right-heart failure $(n=12)$, respiratory failure $(n=10)$, pulmonary hemorrhage $(n=2)$, arrhythmia $(n=2)$ and others $(n=3)$.

\section{Lung function test}

Lung function tests showed no relevant restrictive lung disease with FVC of $80.0 \pm 1.5 \%$ and TLC of $91.0 \pm 1.4 \%$. The ratio of FEV1/FVC x 100 showed no signs of relevant obstructive lung disease in all patients $(70.3 \pm 0.9 \%)$. The diffusing capacity was slightly reduced, to $71.4 \pm 2.1$ predicted. Blood gas analysis showed a mild hypoxemia (pO2 of $63.6 \pm 1.0 \mathrm{~mm} \mathrm{Hg}$ ) and hypocapnia (pCO2 of $33.8 \pm 0.4 \mathrm{~mm} \mathrm{Hg})$.

\section{Hemodynamics}

At initial visit and at rest, PAP was elevated $(41.4 \pm 2.5 \mathrm{~mm}$ $\mathrm{Hg})$, consecutively with a PVR of $624 \pm 70$ dynes * $\mathrm{s} * \mathrm{~cm}-5$, and with a normal PCWP of $9.6 \pm 0.4 \mathrm{mmHg}$. The RAP was elevated with $7.6 \pm 1.1 \mathrm{~mm} \mathrm{Hg}$.

\section{Cardiopulmonary exercise test and six minute walk distance}

Most patients showed a reduction in work capacity of $58.8 \pm 26.4 \%$ with a diminished aerobic capacity of $62.2 \pm 2.1 \%(13.6 \pm 1.3 \mathrm{ml} / \mathrm{min} / \mathrm{kg})$, a reduced $\mathrm{O} 2$ pulse of $9.3 \pm 0.8 \mathrm{ml} / \mathrm{min} /$ beat and elevated ventilatory equivalents for oxygen $(45.9 \pm 2.2)$ and for carbon dioxide $(51.8 \pm 2.2)$ at the AT $(9.0 \pm 0.9 \mathrm{ml} / \mathrm{min} / \mathrm{kg})$. Furthermore, we observed elevated AaDO2 $(56.5 \pm 3.2 \mathrm{mmHg})$ during peak exercise with an elevated a-etCO2 - difference of $7.7 \pm 0.9 \mathrm{mmHg}$. Ve/VCO2 slope amounted to $51.7 \pm 4.3$ with a PetCO2 of $28.0 \pm 0.7 \mathrm{mmHg}$ at peak exercise. The AT could not be determined in 11 patients because of mitigating oscillatory gas exchange patterns or premature end of exercise.

On average, we objectified a six minute walk distance of $314.5 \pm 12.3 \mathrm{~m}$ or $62.4 \pm 2.2 \%$ respectively.

\section{Evaluation of survivors and nonsurvivors in respect of CPET parameters in patients with pulmonary hypertension}

In our study group, no significant differences in any of hemodynamic parameters, aerobic capacity, anaerobic threshold and oxygen pulse at baseline existed between survivors and nonsurvivors. On the other hand, significant differences could be demonstrated in the following parameters at baseline: power capacity (67.7 versus 35.7 watts, $\mathrm{p}=0.023), \mathrm{Ve} / \mathrm{VO} 2$ (42.1 versus $56.9, \mathrm{p}=0.001$ ), Ve/VCO2 (47.5 versus 64.4, $\mathrm{p}<0.001), \mathrm{AaDO} 2(52.8$ versus $67.5 \mathrm{mmHg}, \mathrm{p}=0.009)$ and $\mathrm{Ve} / \mathrm{VCO} 2$ slope $(47.0$ versus 65.4, $\mathrm{p}=0.014$ ) [Table 2].
Table 2 Hemodynamics and Cardiopulmonary exercise characteristics at baseline between survivors and nonsurvivors in patients with selective drug therapy (survival after 24 months)

\begin{tabular}{|c|c|c|c|}
\hline & Survivors & Nonsurvivors & $p$ \\
\hline & $(n=87)$ & $(n=29)$ & \\
\hline PAP, $\mathrm{mmHg}$ & $42.0 \pm 2.5$ & $39.6 \pm 2.6$ & ns \\
\hline $\mathrm{Cl}, \mathrm{L}^{*} \mathrm{~min}-1^{*} \mathrm{~m}-2$ & $2.30 \pm 0.12$ & $2.31 \pm 0.21$ & ns \\
\hline PVR, dynes * s* cm-5 & $633.8 \pm 68.2$ & $594.1 \pm 76.6$ & ns \\
\hline $\mathrm{RAP}, \mathrm{mmHg}$ & $7.22 \pm 0.79$ & $8.55 \pm 1.88$ & ns \\
\hline W, watts & $67.7 \pm 8.0$ & $35.7 \pm 1.5$ & 0.023 \\
\hline $\mathrm{VO} 2, \mathrm{ml} / \mathrm{min} / \mathrm{kg}$ & $14.6 \pm 1.4$ & $10.9 \pm 1.0$ & ns \\
\hline AT, $\mathrm{ml} / \mathrm{min} / \mathrm{kg}$ & $9.65 \pm 0.87$ & $7.09 \pm 1.07$ & ns \\
\hline $\mathrm{O} 2$ pulse, $\mathrm{ml} / \mathrm{min} / \mathrm{beat}$ & $9.80 \pm 0.81$ & $7.79 \pm 0.64$ & ns \\
\hline VeNO2 - AT & $42.1 \pm 2.1$ & $56.9 \pm 2.6$ & 0.001 \\
\hline VeNCO2 - AT & $47.5 \pm 2.2$ & $64.4 \pm 2.3$ & $<0.001$ \\
\hline AaDO2 - peak exercise, $\mathrm{mmHg}$ & $52.8 \pm 2.8$ & $67.5 \pm 4.2$ & 0.009 \\
\hline a-et $\mathrm{CO} 2, \mathrm{mmHg}$ & $6.8 \pm 0.8$ & $10.5 \pm 1.1$ & 0.014 \\
\hline VeNCO2 slope & $47.0 \pm 3.2$ & $65.4 \pm 7.5$ & 0.014 \\
\hline
\end{tabular}

$P A P=$ mean pulmonary artery pressure.

$\mathrm{Cl}=$ cardiac index.

$P V R=$ pulmonary vascular resistance.

$R A P=$ mean right atrial pressure.

$W=$ work capacity.

$V O 2=$ peak oxygen uptake.

$A T=$ anaerobic threshold

$O 2$ pulse = oxygen pulse.

Ve/VO2 = oxygen equivalent at anaerobic threshold

$\mathrm{Ve} / \mathrm{VCO} 2$ = carbon dioxide equivalent at anaerobic threshold.

$A a D O 2=$ alveolar-arterial oxygen difference at peak exercise.

a-et $\mathrm{CO} 2$ = arterial-endexpiratory carbon dioxide difference at peak pexercise.

$\mathrm{Ve}-\mathrm{VCO} 2$ slope = slope of minute ventilation versus carbon dioxide output.

\section{Cardiopulmonary exercise parameters predictors of two-years mortality}

According to the study results from Wensel at al. [2], we firstly investigated the aerobic capacity with a cut-off value of $10.4 \mathrm{ml} / \mathrm{min} / \mathrm{kg}$. In our study population, VO2 (AUC $=0.252$ ) could not predict the two-years mortality with a sensitivity of $27 \%$ and specificity of $69 \%$. The best predictive value in our group was the Ve/VCO2 (with a cut-off value of 55, AUC $=0,769$ ) with a relative risk of two-years mortality of 7.83 and a sensitivity of $80 \%$ and a specificity of $79 \%$ [Figure 1]. Furthermore, Ve/VCO2 slope $(\mathrm{AUC}=0.798)$ with a relative risk of 5.75 showed significant predictive mortality values [Figure 2]. AaDO2 $(\mathrm{AUC}=0.758)$ and a-etCO2 $(\mathrm{AUC}=0.804)$ values at peak exercise was not able to predict the mortality because of a decreased specificity of $62 \% / 69 \%$ [Table 3].

\section{Discussion}

To our knowledge, this is one of the first studies of CPET data in patients with $\mathrm{PAH} / \mathrm{CTEPH}$ to compare ventilatory efficiency parameters as a predictor of 24months mortality. In our study, ventilatory equivalent 


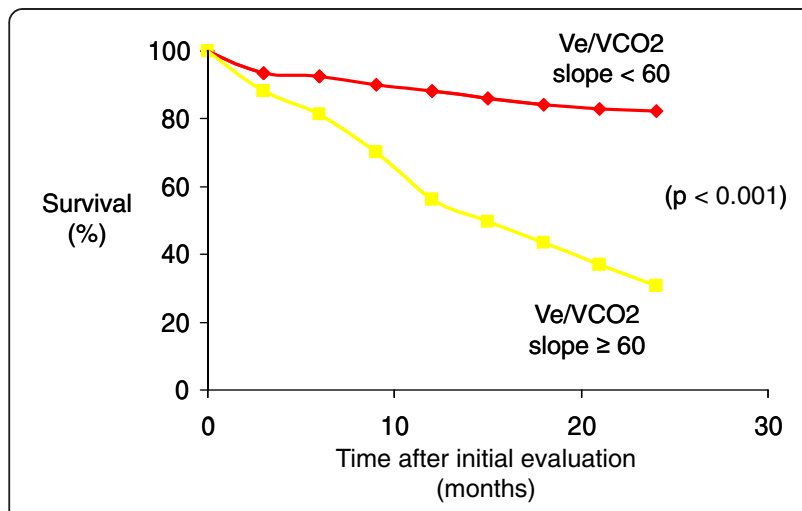

Figure 1 Kaplan-Meier plot relating survival to Ve/VCO2 slope.

for carbon dioxide at anaerobic threshold with a cutoff value of 55 identifies patients with an over seven fold increased risk of death within 24 months after initial evaluation. The Ve/VCO2 slope with a cutoff value of 60 had an over five fold increased risk of death within the same time interval. In our study group the parameters of ventilatory efficiency significantly better predicted the clinical outcome compared to peak oxygen uptake with a cut-off value of $10.4 \mathrm{ml} / \mathrm{min} / \mathrm{kg}$. Taken together, these results support the concept that for example the VE/ $\mathrm{VCO} 2$ slope or the ventilatory equivalents may be prognostically superior to peak VO2.

Symptoms in PAH-patients develop during exercise because recruitment of pulmonary vascular bed needed for exercise is impaired. Three pathophysiologies could be easily identified: [1] failure to perfuse the ventilated lung, thereby increasing the physiologic dead space and ventilatory requirement [5,24,32]; [2] failure to increase cardiac output (oxygen transport) appropriately in response to exercise, causing a low work rate lactic acidosis (increased $\mathrm{CO} 2$ production relative to $\mathrm{O} 2$ consumption), thereby increasing acid ventilatory drive [11,33]; and [3] exercise-induced hypoxemia in most PH patients, thereby increasing the hypoxic ventilatory drive. Ventilatory inefficiency could be measured as an increase in ventilatory equivalents for oxygen and carbon dioxide. Reindl et al. [11] showed that ventilatory

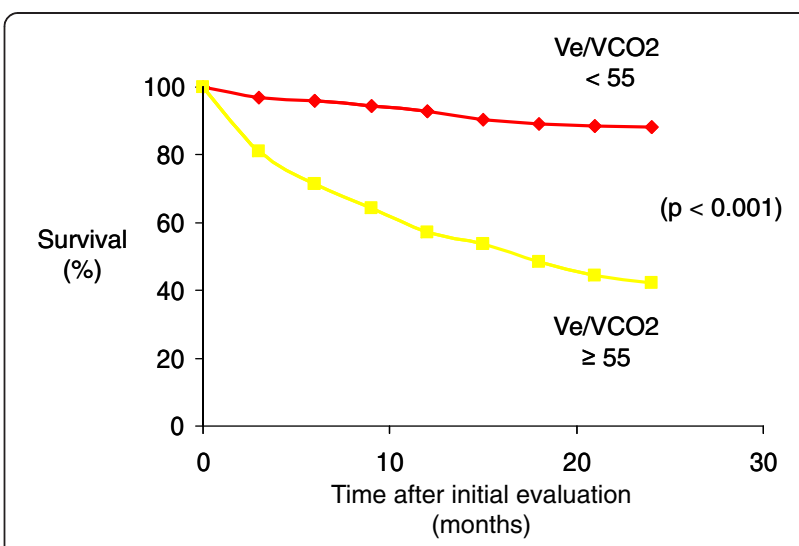

Figure 2 Kaplan-Meier plot relating survival to Ve/VCO2 at anaerobic threshold.

efficiency is influenced by cardiac output and by pulmonary vasoconstriction. Alveolar hypoperfusion, caused by impaired or defective vasodilation, probably represents the link to the impairment of ventilatory efficiency.

A significant finding in our study was the confirmation that $\mathrm{Ve} / \mathrm{VCO} 2$ slope is a strong, independent predictor of death in patients suffering from PAH/CTEPH. This observation is in agreement with other studies from patients with chronic heart failure which have examined the prognostic significance of the $\mathrm{Ve} / \mathrm{VCO} 2$ slope $[15,19,34,35]$. Patients with chronic heart failure ventilate more during exercise than controls, resulting in an increase in the $\mathrm{Ve} / \mathrm{VCO} 2$ slope [36]. The increased Ve/ $\mathrm{VCO} 2$ slope could be a result of different mechanism. Ventilation perfusion mismatch [12,37], impaired diffusion of metabolic gases [38], respiratory muscle weakness [39], and heightened sensitivity of peripheral receptors $[40,41]$ have all been postulated as possible causes. Additionally, one of the proposed mechanisms for an increase in $\mathrm{Ve} / \mathrm{VCO} 2$ slope in chronic heart failure patients is an abnormal pulmonary perfusion [42]. Furthermore, Ukkonen et al. [43] showed that the right ventricular oxidative metabolism correlates with $\mathrm{Ve} /$ VCO2 slope in chronic heart failure patients. This supports the hypothesis that pulmonary vascular resistance is a main determinant of the $\mathrm{Ve} / \mathrm{VCO} 2$ slope [43].

Table 3 Cardiopulmonary exercise parameters predictors of two-years mortality rate in patients in patients with selective drug therapy, ie, in patients with pulmonary artery hypertension and in patients with chronic thromboembolic pulmonary hypertension $(n=116)$

\begin{tabular}{|c|c|c|c|c|}
\hline & \multirow[t]{2}{*}{ Sensitivity } & \multirow[t]{2}{*}{ Specificity } & odds ratio & \multirow[t]{2}{*}{ significance } \\
\hline & & & [95\% confidence interval] & \\
\hline VO2 (< 10.4 ml/min/kg) & $27 \%$ & $69 \%$ & $1.88[1,58 ; 2,18]$ & $p=0.03$ \\
\hline VeNCO2 ( $\geq 55)$ & $80 \%$ & $79 \%$ & $14.66[12,70 ; 16,62]$ & $p=0.004$ \\
\hline $\mathrm{AaDO} 2(\geq 55 \mathrm{mmHg})$ & $69 \%$ & $62 \%$ & $3.67[3,11 ; 4,23]$ & $p=0.09$ \\
\hline Ve/NCO2 slope $(\geq 60)$ & $70 \%$ & $81 \%$ & $9.92[6,68 ; 13,17]$ & $p=0.03$ \\
\hline a-etCO2 ( $\geq 8$ mmHg) & $62 \%$ & $69 \%$ & $3.63[2,73 ; 4,53]$ & $p=0.02$ \\
\hline
\end{tabular}


Because of the increased pulmonary vascular resistance in $\mathrm{PH}$, pulmonary blood flow (cardiac output) fails to increase normally during exercise. The blunted cardiac output response to exercise results in an increase in anaerobic glycolysis with development of a lactic acidosis at low work rates. The lactic acidosis produces acid stimuli that increases ventilatory drive [44].

Mitani et al. [25] suggested that it is necessary - when performing a CPET in PAH patients - to observe not only $\mathrm{VO} 2$ or $\mathrm{VCO} 2$, but also $\mathrm{Ve} / \mathrm{VCO} 2$, in order to prevent aggravation of the ventilation/perfusion inequality, which leads to exercise-induced hypoxemia. A higher $\mathrm{VE} / \mathrm{VCO} 2$ ratio describes a greater ventilatory requirement for eliminating the $\mathrm{CO} 2$ produced by aerobic metabolism and defines a reduced ventilatory efficiency. The reduced ventilatory efficiency is therefore caused by an increase in physiological dead space and a reduced $\mathrm{PaCO} 2$ set-point [45]. Ting et al. [23] demonstrated that patients with higher $\mathrm{Ve} / \mathrm{VCO} 2$ ratio would be patients with higher pulmonary vascular resistance. On the other side, the authors showed that the improvement in VE/ VCO2 ratio paralleled the improvement in VD/VT following dosing with prostanoids. This supports the concept that a reduction in $\mathrm{Ve} / \mathrm{VCO} 2$ ratio reflects an improvement in blood flow to the ventilated lung. Reybrouck et al. [24] found that the $\mathrm{Ve} / \mathrm{VCO} 2$ slope was steeper in patients with $\mathrm{PH}$ than the slope in patients with normal PAP, and these authors found a significant correlation between the slope and PAP and the VD/VT. Because of ventilation-perfusion inequalities, the VD/VT is increased, making gas exchange less efficient than normal. This causes PetCO2 to be diluted relative to $\mathrm{PaCO} 2$. Because pulmonary vascular disease is the hallmark of patients with $\mathrm{PH}$, it is likely that the remarkably low PetCO2 seen in our patients with $\mathrm{PH}$ is partially due to underperfusion of ventilated lung.

Our data indicate that abnormally reduced ventilatory efficiency parameters are powerful and independent predictors of mortality in patients with PAH/CTEPH. Our study demonstrates that an increased ventilatory response to exercise is associated with a lower survival in patients with stable PAH. For several years, peak VO2 was the "gold standard" and remains widely used to risk stratify this type of patients [2]. However, the limitations of peak $\mathrm{VO} 2$ have prompted the search for other indices of CPET that can serve as alternative prognostic factors. The main disadvantage of peak $\mathrm{VO} 2$ is the need for maximal exercise, which may be difficult to achieve, particularly in PAH patients, whose daily activity levels are far below the effort required by the test. In addition, peak VO2 may be underestimated because of low patient motivation or because of premature termination of the test by the physician. Thus supplementary indices are needed to sharpen the risk stratification [46]. Unlike peak $\mathrm{VO} 2$, for example the $\mathrm{Ve} / \mathrm{VCO} 2$ slope is generally independent from subject effort. In addition, variation in the $\mathrm{Ve} / \mathrm{VCO} 2$ slope appears to rely closely on central function in patients with $\mathrm{PH}$. The closer reliance the $\mathrm{Ve} /$ VCO2 slope has on cardiac performance may contribute to its prognostic accuracy relative to peak $\mathrm{VO} 2$.

\section{Conclusion}

The ventilatory efficiency parameters are easily measurable and highly reproducible parameters obtained from $\mathrm{CPET}$, and the prognostic value of a reduced ventilatory efficiency suggests higher than the peak VO2 alone. Thus, a rational and pragmatic risk stratification process should include both peak VO2 and ventilatory efficiency parameters, and in particular, the measurement of the $\mathrm{Ve} / \mathrm{VCO} 2$ slope and ventilatory equivalent for carbon dioxide should be performed in patients with $\mathrm{PAH} /$ СТЕРН. In summary, based upon these preliminary results, we propose that these indices of CPET might be helpful in the care of these patients and could play a role as a prognostic effort-independent marker in the evaluation of PAH/CTEPH patients.

\section{Abbreviations \\ AaDO2: Alveolar-arterial oxygen difference; AT: Anaerobic threshold; AUC: Area under curve; BMI: Body mass index; Cl: Cardiac index; CPET: Cardiopulmonary exercise testing; CTEPH: Chronic thromboembolic pulmonary hypertension; FVC: Forced vital capacity; O2 pulse: Oxygen pulse; PAH: Pulmonary arterial hypertension; PAP: Pulmonary arterial pressure; PCWP: Pressure in wedge position; $\mathrm{PH}$ : Pulmonary hypertension; PVR: Pulmonary vascular resistance; RA: Right atrium pressure; RHC: Right heart catheterization; SO2: Oxygen saturation; TLC: Total lung capacity; TLCo: Diffusing capacity for carbon monoxide; VCO2: Carbon dioxide output; Ve: Minute ventilation; Ve/NCO2: Ventilatory equivalent for carbon dioxide; VeNO2: Ventilatory equivalent for oxygen; Ve/NCO2 slope: Slope between minute ventilation and carbon dioxide production; VO2: Oxygen uptake.}

\section{Competing interests}

The authors declare that they have no competing interests.

\section{Authors' contributions}

Drs. SVS and B conceived and designed the study. Dr. S performed the statistical analyses and drafted the article. Drs. SF and B acquired the study data. All authors participated in interpreting the data and revising the manuscript for important intellectual content. All authors approved the final version of the manuscript.

Received: 7 April 2011 Accepted: 7 June 2012

Published: 7 June 2012

\section{References}

1. Oudiz R, Barst R, Hansen J, et al: Cardiopulmonary exercise testing and sixminute walk correlations in pulmonary arterial hypertension. Am J Cardiol 2006, 97:123-126.

2. Wensel R, Opitz C, Anker S, et al: Assessment of survival in patients with primary pulmonary hypertension. Importance of cardiopulmonary exercise testing. Circulation 2002, 106:319-324.

3. Miyamoto S, Nagaya N, Satoh T, et al: Clinical correlates and prognostic significance of six-minute walk test in patients with primary pulmonary hypertension. Comparison with cardiopulmonary exercise testing. $A, J$ Respir Crit Care Med 2000, 161:487-492.

4. Riley M, Porszasz J, Engelen M, Brundage B, Wasserman K: Gas exchange responses to continuous incremental cycle ergometry exercise in 
primary pulmonary hypertension in humans. Eur J Appl Physiol 2000, 83:63-70.

5. Sun X, Hansen J, Oudiz R, Wasserman K: Exercise pathophysiology in patients with primary pulmonary hypertension. Circulation 2001, 104:429-435.

6. Sun X, Hansen J, Oudiz R, Wasserman K: Gas exchange detection of exercise-induced right-to-left shunt in patients with primary pulmonary hypertension. Circulation 2002, 105:54-60.

7. Hansen J, Sun X, Yasunobu Y, et al: Reproducibility of cardiopulmonary exercise measurements in patients with pulmonary arterial hypertension. Chest 2004, 126:816-824.

8. Markowitz D, Systrom D: Diagnosis of pulmonary vascular limit to exercise by cardiopulmonary exercise testing. J Heart Lung Trans 2004, 23:88-95.

9. Nagaya N, Shimizu Y, Satoh T, et al: Oral beraprost sodium improves exercise capacity and ventilatory efficiency in patients with primary or thromboembolic pulmonary hypertension. Heart 2002, 87:340-345.

10. Yasunobu Y, Oudiz R, Sun X, Hansen J, Wasserman K: End-tidal PCO2 abnormality and exercise limitation in patients with primary pulmonary hypertension. Chest 2005, 127:1637-1646.

11. Reindl I, Wernecke K, Opitz C, et al: Impaired ventilatory efficiency in chronic heart failure: possible role of pulmonary vasoconstriction. Am Heart J 1998, 136:778-785.

12. Lewis N, Banning A, Cooper J, et al: Impaired matching of perfusion and ventilation in heart failure detected by 133xenon. Basic Res Cardiol 1996, 91(suppl 1):45-49.

13. Arena R, Myers J, Aslam S, Varughese E, Peberdy M: Peak VO2 and VE/ VCO2 slope in patients with heart failure: A prognostic comparison. Am Heart J 2004, 147:354-360.

14. Chua T, Ponikowski P, Harrington D, et al: Clinical correlates and prognostic significance of the ventilatory response to exercise in chronic heart failure. J Am Coll Cardiol 1997, 29:1585-1590.

15. Kleber $F$, Vietzke $G$, Wernecke $K$, et al: Impairment of ventilatory efficiency in heart failure: prognostic impact. Circulation 2000, 101:2803-2809.

16. Francis D, Shamim W, Davies $L$, et al: Cardiopulmonary exercise testing for prognosis in chronic heart failure: continuous and independent prognostic value from VE/VCO(2) slope and peak VO(2). Eur Heart J 2000, 21:154-161.

17. Davies L, Francis D, Piepoli M, Scott A, Ponikowski P, Coats A: Chronic heart failure in the elderly: value of cardiopulmonary exercise testing in risk stratification. Heart 2000, 83:147-151

18. Corra U, Mezzani A, Bosimini E, Scapellato F, Imparato A, Giannuzzi P. Ventilatory response to exercise improves risk stratification in patients with chronic heart failure and intermediate functional capacity. Am Heart J 2002, 143:418-426.

19. Gitt A, Wasserman K, Kilkowski C, et al: Exercise anaerobic threshold and ventilatory efficiency identify heart failure patients for high risk of early death. Circulation 2002, 106:3079-3084.

20. Witte K, Thackray S, Nikitin N, Cleland J, Clark A: Pattern of ventilation during exercise in chronic heart failure. Heart 2003, 89:610-614.

21. Guazzi M, Myers J, Arena R: Cardiopulmonary exercise testing in the clinical and prognostic assessment of diastolic heart failure. J Am Coll Cardiol 2005, 46:1883-1890

22. Guazzi M, Raimondo R, Vicenzi M, et al: Exercise oscillatory ventilation may predict sudden cardiac death in heart failure patients. J Am Coll Cardiol 2007, 50:299-308.

23. Ting $H$, Sun $X$, Chuang $M$, Lewis $D$, Hansen J, Wasserman $K$ : A noninvasive assessment of pulmonary perfusion abnormality in patients with primary pulmonary hypertension. Chest 2001, 119:824-832.

24. Reybrouck T, Mertens L, Schulze-Neick I, et al: Ventilatory inefficiency for carbon dioxide during exercise in patients with pulmonary hypertension. Clin Physiol 2008, 28:337-344.

25. Mitani R, Haraguchi M, Takata S, et al: Excessive ventilatory response during exercise in patients with non-hypoxic pulmonary hypertension. Circ J 2002, 66:453-456.

26. Humbert M, McLaughlin V: Proceedings of the $4^{\text {th }}$ World Symposium on Pulmonary Hypertension. J Am Coll Cardiol 2009, 54:S1-S116.

27. ESC/ERS Guidelines: Guidelines for the diagnosis and treatment of pulmonary hypertension. Eur Heart J 2009, 30:2493-2537.

28. Quanjer P, Tammeling G, Cotes J, et al: Lung volumes and forced ventilatory flows: Report Working Party Standardization of Lung
Function Tests; European Community for Steel and Coal. Official Statement of the European Respiratory Society. Eur Respir J Supp/ 1993, 16:5-40

29. McEvoy J, Jones N: Arterialized capillary blood gases in exercise studies. Med Sci Sports 1975, 7:312-315.

30. American Thoracic Society: Guidelines for the six-minute walk test. ATS statement. Am J Respir Crit Care Med 2002, 166:111-117.

31. Wasserman K, Hansen J, Sue D, Stringer W, Whipp B: Principles of Exercise Testing and Interpretation. 4th edition. Baltimore, MD: Lippincott Williams \& Wilkens; 2004

32. Fukuchi K, Hayashida K, Nakanishi N, et al: Quantitative analysis of lung perfusion in patients with primary pulmonary hypertension. J Nucl Med 2002, 43:757-761.

33. Tabet J, Beauvais F, Thabut G, Tartiere J-M, Logeart D, Cohen-Solal A: A critical appraisal of the prognostic value of the VE/VCO2 slope in chronic heart failure. Eur J Cardiovasc Prev Reha 2003, 10:267-272.

34. Guazzi M, de Vita S, Cardano P, Barlera S, Guazzi M: Normalization for peak oxygen uptake increases the prognostic power of the ventilatory response to exercise in patients with chronic heart failure. Am Heart $J$ 2003, 146:542-548

35. Nanas S, Nanas J, Sakellariou D, et al: Ve/VCO2 slope is associated with abnormal resting haemodynamics and is a predictor of long-term survival in chronic heart failure. Eur J Heart Fail 2006, 8:420-427.

36. Wasserman $K$, Zhang $Y$, Gitt A, et al: Lung function and exercise gas exchange in chronic heart failure. Circulation 1997, 96:2221-2227.

37. Wada $\mathrm{O}$, Asanoi $\mathrm{H}$, Miyagi $\mathrm{K}$, et al: Importance of abnormal lung perfusion in excessive exercise ventilation in chronic heart failure. Am Heart J 1993, 125:790-798.

38. Puri S, Baker B, Oakley C, Hughes J, Cleland J: Increased alveolar/capillary membrane resistance to gas transfer in patients with chronic heart failure. Br Heart J 1994, 72:140-144.

39. Daganou M, Dimopoulou I, Alivizatos P, Tzelepis G: Pulmonary function and respiratory muscle strength in chronic heart failure: comparison between ischaemic and idiopathic dilated cardiomyopathy. Heart 1999, 81:618-620.

40. Chua T, Clark A, Amadi A, Coats A: Relation between chemosensitivity and the ventilatory response to exercise in chronic heart failure. J Am Coll Cardiol 1996, 27:650-657.

41. Narkiewicz K, Pesek C, van de Borne P, Kato M, Somers V: Enhanced sympathetic and ventilatory responses to central chemoreflex activation in heart failure. Circulation 1999, 100:262-267.

42. Johnson R: Gas exchange efficiency in congestive heart failure. Circulation 2000, 101:2774-2776.

43. Ukkonen $\mathrm{H}$, Burwash I, Dafoe $\mathrm{W}$, et al: Is ventilatory efficiency (VE/VCO2 slope) associated with right ventricular oxidative metabolism in patients with congestive heart failure. Eur J Heart Fail 2008, 10:1117-1122.

44. Arzt M, Harth M, Luchner A, et al: Enhanced ventilatory response to exercise in patients with chronic heart failure and central sleep apnea. Circulation 2003, 107:1998-2003.

45. Habedank D, Reindl I, Vietzke G, Bauer U, Sperfeld A: Ventilatory efficiency and exercise tolerance in 101 healthy volunteers. Eur J Appl Physiol 1998, 77:412-426.

46. Van Laethem C, Bartunek J, Goethals M, Nellens P, Andries E, Vanderheyden M: Oxygen uptake efficiency slope, a new submaximal parameter in evaluating exercise capacity in chronic heart failure patients. Am Heart $J$ 2005, 149:175-180

\section{doi:10.1186/1471-2466-12-23}

Cite this article as: Schwaiblmair et al:: Ventilatory efficiency testing as prognostic value in patients with pulmonary hypertension. BMC Pulmonary Medicine 2012 12:23. 